\title{
Effects of Yeast Glucomannan and Sodium Bentonite on the Toxicity of Aflatoxin in Broilers
}

http://dx.doi.org/10.1590/1516-635xSpeciallssue Nutrition-PoultryFeedingAdditives007-014

nAuthor(s)

Azizpour $A^{\prime}$

Moghadam N"

Meshginshahr Faculty of Agriculture, University of Mohaghegh Ardabili, Ardabil, Iran.

" Department of Poultry Diseases, Science and Research Branch, Islamic Azad University, Tehran, Iran.

\section{Mail Address}

Corresponding author e-mail address Navid Moghadam

Department of Poultry Diseases, Science and Research Branch, Islamic Azad University, Tehran, Iran.

E-mail: Navid_vet80@yahoo.com

\section{EKeywords}

Aflatoxin, biochemical parameters, broilers, pathological changes, yeast glucomannan.

\section{ABSTRACT}

The aim of this study was to evaluate the efficacy of a yeast glucomannan $(Y G)$ and sodium bentonite $(S B)$ in reducing the toxicity of aflatoxin for broilers fed a diet naturally contaminated with aflatoxin. In total, 300 7-day-old Ross 308 broilers were randomly assigned to 10 dietary treatments, consisting of a diet with no aflatoxin (positive control), a diet naturally contaminated with $250 \mathrm{ppb}$ aflatoxin (negative control), and eight aflatoxin-contaminated diets supplemented with different SB and YG and their combinations. Serum biochemical parameters and liver pathological changes were investigated when broilers were 42 days old. The birds fed the negative control diet presented lower uric acid, cholesterol, and triglyceride levels and higher in AST and ALT activities compared with the positive control group. In addition, negative-control birds also showed significant histopathological changes $(p<0.05)$, including slight to moderate hydropic degeneration and/or fatty changes (8 cases), bile-duct hyperplasia (7 cases), periportal fibrosis ( 5 cases), cells infiltration (4 cases), congestion (3 cases) as well gross pathological changes. The addition of $Y G$ and $S B$ to the aflatoxin-contaminated diet partially alleviated the negative effects of aflatoxin. However, the supplementation $0.1 \%$ YG alone to the aflatoxin-contaminated diet significantly prevented the adverse effects of aflatoxin on serum biochemical parameters and pathological liver changes and was found to be more effective than other treatments.

\section{INTRODUCTION}

Aflatoxins are potent mycotoxins produced mainly by Aspergillus flavus and Aspergillus parasiticus. They are considered a significant problem in poultry production and public health because they cause considerable economic losses and severe health problems.

Various symptoms are associated with aflatoxicosis in poultry. The most common are weakness, anorexia with reduced growth rate, poor feed utilization, slow weight gain, decreased egg weight and production, and increased mortality (Oguz et al., 2000). The toxicity of aflatoxin in poultry has been extensively studied to determine their teratogenic, carcinogenic, mutagenic, and growth-inhibition effects (Oznurlu et al., 2012). The biochemical, hematological (Basmacioglu et al., 2005; Azizpour et al., 2012), immunological (Mogadam \& Azizpour, 2011), and pathological (Ortatatli \& Oguz, 2001) effects of aflatoxins have also been described in depth. Aflatoxins may also cause significant gross and microscopic changes in the liver, such as hepatomegaly, paleness, hydropic degeneration, fatty liver, bile-duct hyperplasia, and periportal fibrosis (Karaman et al., 2005; Ortatatli et al., 2005).

Preventing mold growth and aflatoxin contamination of feeds and feedstuffs essential, but when contamination is inevitable, aflatoxin must be inactivated before these materials are used. Producers, 
researchers, and governments have tried to apply efficient prevention management practices and decontamination technologies to minimize the toxic effects of aflatoxin in animal production. In addition to prevention strategies, other novel approaches including physical, chemical, and biological treatments to detoxify aflatoxin in contaminated feeds and feedstuffs have been employed (Parlat et al., 2001).

Since the early 1990s, studies on adsorbents-based strategies to eliminate mycotoxins from contaminated feeds and to minimize their effects of toxicity on poultry health have been carried out (Oguz, 2012). Zeolites (Modirsanei et al., 2004; Khadem et al., 2012), bentonites (Ibrahim et al., 2000; Rosa et al., 2001; Eraslan et al., 2004; Abousadi et al., 2007; Manafi, 2009; 2012), and yeast and esterified glucomannans (Raju \& Devegowda, 2000; Aravind et al., 2003; Girish \& Devegowda, 2006; Che et al., 2011; Mosca \& Marichal, 2011; Rosa et al., 2012) have been shown to reduce aflatoxin absorption in the gastrointestinal tract. Some studies suggest that the best approach for decontamination is biological degradation, using yeast and yeast components, which may remove aflatoxin under mild conditions, without having to use harmful chemicals or causing any noticeable losses in the nutritional value or palatability of diets (Shetty et al., 2007; Oguz, 2012).

The objectives of the present study was to evaluate the toxic effects of aflatoxin (250 ppb) on serum biochemical parameters and liver gross and microscopic changes in broilers, and to determine the possible preventive effects of the dietary addition of a glucomannan-containing yeast product (Mycosorb; $0.05 \%$ and $0.1 \%)$ and sodium bentonite (1.5\% and $3 \%$ ) on serum biochemical parameters and pathological changes induced by aflatoxin in broilers.

\section{MATERIALS AND METHODS}

\section{Birds and diets}

In total, 325 one-day-old Ross 308 male broilers were obtained from a commercial broiler producer. Birds were submitted to a 7-day adaptation period before the beginning of the trial. Subsequently, birds were submitted to commercial broiler management practices and housed in an environmentally controlled broiler house on floor pens with litter.

Three hundred birds, with similar body weight, were randomly designated to 30 pens. They were fed a commercial starter feed (based on corn and soybean meal, containing $20.84 \%$ CP, 2900.29 ME) up to 21 days of age and a grower diet (19.68\% CP, $3150 \mathrm{ME})$ from
22 to 42 days. Birds had access to feed and water ad libitum from one to 42 days of age. The basal diet was supplemented with amino acids, mineral and vitamins at the levels recommended by the National Research Council (NRC, 1994), and did not contain any antibiotics, coccidiostats, or growth promoters. In addition, birds were inspected daily and any health problem was recorded. Lighting was supplied for $23 \mathrm{~h}$ daily.

\section{Treatments}

The birds (three replicates of 10 chicks each) were designated to the following treatment groups: 1) positive control diet, consisting of the basal diet with no aflatoxin or additives (control); 2) negative control diet, consisting of a diet naturally contaminated with aflatoxin (250 ppb; NCD); 3) NCD supplemented with $1.5 \%$ sodium bentonite (SB); 4) NCD supplemented with $3 \%$ SB; 5) NCD supplemented with $0.05 \%$ yeast glucomannan (YG); 6) NCD supplemented with $0.1 \%$ YG; 7) NCD supplemented with $1.5 \%$ SB+ $0.05 \%$ YG; 8) NCD supplemented with $1.5 \% \mathrm{SB}+0.1 \% \mathrm{YG}$; 9) NCD supplemented with $3 \%$ SB $+0.05 \%$ YG; and 10$)$ NCD supplemented with 3\% SB+0.1\% YG

\section{Aflatoxin quantification and diet preparation}

Individual feed ingredients were analyzed and screened for aflatoxin content. Aflatoxin was extracted according to Romer (1975), and quantified by thinlayer chromatography (TLC). The basal control diet was formulated to supply the nutritional requirements of commercial broilers (NRC, 1994) during the starter and grower periods.

The basal diet did not contain any detectable aflatoxin levels (below $1 \mu \mathrm{g} / \mathrm{kg}$ diet; ppb). Corn was obtained from a private feed mill (already contaminated with mold) and was stored at $20 \%$ moisture for two months to promote mold growth. The presence of aflatoxin in the corn was confirmed by TLC. Aflatoxinfree corn was replaced with naturally contaminated corn in the formulation of the contaminated-diet treatments. The samples were randomly selected from four different portions of the whole sample. The analysis of the contaminated diet showed it contained 250 ppb aflatoxin (detection limit: 1 ppb). The aflatoxin in the contaminated diet was composed of $84.72 \%$ AFB1, 5.50\% AFB2, 8.20\% AFG1, and 1.58\% AFG2.

During the experimental period, the control and the contaminated diets were analyzed for aflatoxin and other mycotoxins. The levels of aflatoxin in the control diet were below the detection limits. Aflatoxin levels in the contaminated diet ranged from 240 to $250 \mathrm{ppb}$. The presence of other mycotoxins was not detected. 


\section{Serum biochemistry}

At the end of the trial, when broilers were 42 days old, 10 birds per treatment were randomly selected for blood collection from the wing vein for biochemical analysis. Blood was centrifuged at $1400 \times \mathrm{g}$ at $8^{\circ} \mathrm{C}$ for 30 min (Sorvall, RC 3 B plus) and the serum separated and preserved at $-20^{\circ} \mathrm{C}$ until biochemical analyses. Serum concentrations of cholesterol, uric acid, triglycerides, and the activities of the enzymes aspartate aminotransferase (AST) and alanine aminotransferase (ALT) were determined using an automatic analyzer (Tokyo Boeki, TMS, 1024, Japan) with commercial test kits (Spinreact, Spain).

\section{Pathological examination}

After blood collection, the 10 previously selected birds were weighed and euthanized for pathological examination. The liver was removed, cleaned, weighed, and its relative weight ( $\mathrm{g}$ liver/100 $\mathrm{g}$ live body weight) was calculated. Liver tissue samples were collected in $10 \%$ neutral buffered formalin. Upon fixation, samples were dehydrated in graded alcohol series, cleared in xylene, and embedded in paraffin wax. Ten- $\mu \mathrm{m}$ sections were cut and stained with hematoxylin and eosin (H\&E; Thermo Shandon, 15275, USA).

Livers were scored for microscopic hepatocellular changes and degeneration as follows:

- Degree 1 (mild): mild hepatocellular swelling due to hydropic degeneration and fatty changes only in centrilobular areas.

- Degree 2 (moderate): clear hepatocellular swelling and changes in both centrilobular and midzonal areas.
- Degree 3 (severe): dispersed and severe hepatocellular swelling and changes in other areas (this grade was not observed in any treatment).

The remaining broilers in each group were used to evaluate growth performance and immunological variables. The results have been published elsewhere (Mogadam and Azizpour, 2011).

\section{Ethical considerations}

The experiment procedures were approved by the Commission of Ethics and Animal Welfare of the Islamic Azad University under protocol number 1235.

\section{Statistical analysis}

The experiment was analyzed according to a completely randomized design with 10 dietary treatments with three replicates of 10 birds each. Data were subjected to statistical analysis using the general linear models procedure of SAS software (SAS, 1996). Treatment means showing significant differences in the one-way analysis of variance were compared using Duncan's multiple-range test. Histopathological lesions were compared among treatment groups by the chisquare test. All the statements of significance were based on 0.05 probability level.

\section{RESULTS}

\section{Serum biochemistry}

The effects of the dietary treatments on serum biochemical parameters are presented in Table 1. Feeding aflatoxin alone caused significant reduction in

Table 1 - Effect of aflatoxin-contaminated diet, sodium bentonite (SB) and yeast glucomannan (YG) on serum biochemical parameters and relative liver weight in broiler chicks fed aflatoxin contaminated feed from 7 to 42 days of age.

\begin{tabular}{|c|c|c|c|c|c|c|}
\hline \multirow{2}{*}{ Treatments* } & \multicolumn{6}{|c|}{42 days of age } \\
\hline & Uric acid (mg/dl) & Cholesterol (mg/dl) & Triglyceride (mg/dl) & AST (iu/l) & ALT (iu/l) & Relative liver weight(g) \\
\hline 1 & $7.68 \pm 2.20^{\mathrm{a}}$ & $165.16 \pm 1.75$ & $159.09 \pm 44.85^{a}$ & $241.82 \pm 32.92^{b}$ & $38.25 \pm 2.52^{b}$ & $2.3 \pm 1.2^{c}$ \\
\hline 2 & $3.65 \pm 0.27^{b}$ & $116.02 \pm 8.79$ & $72.83 \pm 58.80^{c}$ & $321.53 \pm 25.24^{a}$ & $53.10 \pm 7.95^{a}$ & $5.1 \pm 1.3^{a}$ \\
\hline 3 & $4.08 \pm 1.36^{b}$ & $140.83 \pm 10.72$ & $98.07 \pm 10.03^{b c}$ & $309.93 \pm 34.05^{\mathrm{ab}}$ & $47.92 \pm 5.64^{\mathrm{ab}}$ & $4.2 \pm 0.8^{\mathrm{ab}}$ \\
\hline 4 & $3.98 \pm 2.20^{\mathrm{b}}$ & $132.42 \pm 14.48$ & $79.50 \pm 26.90^{c}$ & $303.27 \pm 29.93^{\mathrm{ab}}$ & $48.17 \pm 3.34^{\mathrm{ab}}$ & $4.5 \pm 0.7^{a b}$ \\
\hline 5 & $4.30 \pm 0.54^{\mathrm{ab}}$ & $147.11 \pm 9.56$ & $81.16 \pm 5.75^{c}$ & $305.39 \pm 40.72^{\mathrm{ab}}$ & $44.13 \pm 6.45^{\mathrm{ab}}$ & $3.5 \pm 0.9^{b c}$ \\
\hline 6 & $6.35 \pm 0.60^{a}$ & $175.93 \pm 9.45$ & $144.89 \pm 29.20^{a}$ & $265.42 \pm 18.63^{b}$ & $41.72 \pm 1.98^{b}$ & $2.9 \pm .0 .5^{c}$ \\
\hline 7 & $4.24 \pm 0.44^{\mathrm{ab}}$ & $131.16 \pm 3.40$ & $91.81 \pm 14.64^{\mathrm{bc}}$ & $306.63 \pm 52.48^{\mathrm{ab}}$ & $45.49 \pm 7.20^{\mathrm{ab}}$ & $4.3 \pm 1.1^{a b}$ \\
\hline 8 & $4.12 \pm 0.52^{b}$ & $142.50 \pm 6.26$ & $83.63 \pm 21.86^{\mathrm{bc}}$ & $307.91 \pm 60.04^{\mathrm{ab}}$ & $46.65 \pm 4.35^{\mathrm{ab}}$ & $4.4 \pm 1.2^{\mathrm{ab}}$ \\
\hline 9 & $4.36 \pm 0.47^{a b}$ & $143.16 \pm 17.92$ & $82.05 \pm 12.21^{\mathrm{bc}}$ & $301.60 \pm 72.83^{\mathrm{ab}}$ & $46.12 \pm 9.43^{\mathrm{ab}}$ & $3.7 \pm 1.4^{\mathrm{abc}}$ \\
\hline 10 & $4.68 \pm 2.05^{\mathrm{ab}}$ & $141.92 \pm 13.32$ & $119.71 \pm 20.25^{\mathrm{ab}}$ & $294.52 \pm 81.46^{\mathrm{ab}}$ & $43.32 \pm 8.16^{\mathrm{ab}}$ & $3.5 \pm 1.1^{b c}$ \\
\hline Sig. & ** & NS & ** & ** & ** & ** \\
\hline
\end{tabular}

a-b: means presented in a column with different superscripts differ significantly $\left.(\mathrm{p}<0.05) .{ }^{*} 1\right)$ Positive control diet, basal diet without additive(control); 2$)$ Negative control diet, diet naturally contaminated with aflatoxin (NCD); 3) NCD supplemented with $1.5 \% \mathrm{SB} ; 4)$ NCD supplemented with $3 \% \mathrm{SB} ; 5)$ NCD supplemented with $0.05 \%$ YG; 6) NCD supplemented with $0.1 \%$ YG ; 7) NCD supplemented with $1.5 \%$ SB $+0.05 \%$ YG ; 8) NCD supplemented with $1.5 \%$ SB+0.1\% YG ; 9) NCD supplemented with $3 \%$ SB + 0.05\% YG; and 10$)$ NCD supplemented with $3 \% \mathrm{SB}+0.1 \%$ YG.SB $=$ sodium bentonite . YG $=$ Yeast Glucomannan.NS = Not significant, ${ }^{* *}(p<0.05)$. 


\section{Effects of Yeast Glucomannan and Sodium Bentonite on the Toxicity of Aflatoxin in Broilers}

uric acid (52.4\%) and triglyceride (54.22\%) levels, and significantly increased AST (32.96\%) and ALT (34.82\%) activities $(p<0.05)$ compared with the control group. Total cholesterol $(29.75 \%)$ level of the group fed only with aflatoxin was not statistically different $(p>0.05)$ from the control group.

The addition of YG $(0.1 \%)$ alone to the aflatoxincontaining diet (250 ppb; group 6) significantly alleviated the adverse effects of aflatoxin on uric acid and triglyceride serum levels, AST and ALT activities, and liver relative weight $(p<0.05)$. The other adsorbent treatments (groups 3, 4, 5, 7, 8, 9, 10) tended to promote only partial amelioration of the parameters negatively affected by the aflatoxin treatment ( $p>0.05$ ).

\section{Liver pathological changes}

The aflatoxin-contaminated diet caused a significant increase $(p<0.05)$ in liver relative weight compared with the non-contaminated diet (5.1 vs. 2.3; 121.7\%).

No significant microscopic lesions were observed in liver tissue of the control birds (Table 2). The number of birds fed the aflatoxin-contaminated diet presenting liver damage was significantly higher $(p<0.05)$ compared with the positive control group. The lesions included slight to moderate hydropic degeneration and fatty vacuoles in hepatocytes in centrilobular and midzonal areas (8 of 10 cases; Fig. 1). In this group, bile duct proliferation (7 of 10 cases) was observed in the portal areas (Fig. 2), as well as periportal fibrosis (5 of 10 cases), cell infiltration (4 of 10 cases; Fig. 3), and a slight hyperemia (3 of 10 cases). There were also histopathological changes (slight to moderate) in the livers of birds submitted to the other treatments.

The addition of $Y G$ alone (groups 5 and 6) and YG+SB (group 10) to the aflatoxin-contaminated diet significantly reduced the number of affected broilers and/or the severity of lesions (Table 2). The reduction in the severity of hydropic degeneration and other liver changes was considerable. Liver relative weight was also recovered by $Y G(0.05$ and $0.1 \%)$ and $Y G$ $(0.1 \%)+$ SB $(3 \%)$ treatments (groups 5,6 and 10; $\mathrm{p}<0.05)$. Treatment $6(0.1 \% \mathrm{YG})$ presented the mildest histopathological lesions (slight hydropic degeneration) relative to the other treatments, except relative to the positive control group.

\section{DISCUSSION}

Due to their high toxicity and frequency of occurrence in feedstuffs, aflatoxin is an important issue in the poultry industry. Aflatoxin-contaminated feed reduces the activities of several enzymes that are important for the digestion of carbohydrates, proteins, lipids, and nucleic acids in broilers (Oguz et al., 2011). Chronic and sub-clinical aflatoxicosis cases can be diagnosed by determining changes in serum biochemistry and hematological parameters before clinical symptoms become apparent. These parameters are sensitive indicators of aflatoxicosis (Kececi et al., 1998).

The biochemical and hematological toxic effects of aflatoxin have been well-investigated and are wellknown. Some of the previously described biochemical toxic effects of aflatoxin were clearly seen in present study. Lower uric acid, cholesterol, and triglyceride serum levels, and higher AST and ALT activities were detected in the broilers fed the aflatoxin-contaminated diet with no adsorbents (negative control group) compared with the positive control feed, in agreement with previous reports on the biochemical toxic effects of aflatoxin (Raju \& Devegowda, 2000; Basmacioglu et al., 2005; Mohamed \& Mohamed, 2009; Magnoli et al., 2011). The higher AST and ALT activities and

Table 2 - Effect of aflatoxin-contaminated diet, sodium bentonite (SB) and yeast glucomannan (YG) on microscopic changes of liver in broiler chicks fed aflatoxin contaminated feed from 7 to 42 days of age

\begin{tabular}{|c|c|c|c|c|c|c|c|c|c|c|}
\hline \multirow{2}{*}{ Changes/lesions } & \multicolumn{10}{|c|}{ Treatments* } \\
\hline & 1 & 2 & 3 & 4 & 5 & 6 & 7 & 8 & 9 & 10 \\
\hline $\begin{array}{l}\text { Hydropic degeneration } \\
\text { and/or fatty changes }\end{array}$ & $0 / 10^{b}$ & $8 / 10^{\mathrm{a}}$ & $8 / 10^{a}$ & $7 / 10^{a}$ & $4 / 10^{\mathrm{ab}}$ & $3 / 10^{b}$ & $6 / 10^{\mathrm{a}}$ & $7 / 10^{a}$ & $7 / 10^{\mathrm{a}}$ & $4 / 10^{\mathrm{ab}}$ \\
\hline Bile-duct hyperplasia & $0 / 10^{b}$ & $7 / 10^{a}$ & $4 / 10^{a}$ & $5 / 10^{\mathrm{ab}}$ & $1 / 10^{b}$ & $0 / 10^{b}$ & $5 / 10^{\mathrm{a}}$ & $4 / 10^{a b}$ & $4 / 10^{\mathrm{ab}}$ & $2 / 10^{b}$ \\
\hline Periportal fibrosis & $0 / 10^{b}$ & $5 / 10^{a}$ & $4 / 10^{a}$ & $3 / 10^{a b}$ & $0 / 10^{b}$ & $0 / 10^{b}$ & $3 / 10^{a b}$ & $3 / 10^{a b}$ & $2 / 10^{b}$ & $1 / 10^{b}$ \\
\hline Cell infiltration & $0 / 10^{b}$ & $4 / 10^{a}$ & $2 / 10^{a b}$ & $2 / 10^{a b}$ & $0 / 10^{b}$ & $0 / 10^{b}$ & $2 / 10^{a b}$ & $1 / 10^{b}$ & $2 / 10^{a b}$ & $0 / 10^{b}$ \\
\hline Hyperemia & $0 / 10^{a}$ & $3 / 10^{\mathrm{a}}$ & $2 / 10^{a}$ & $1 / 10^{a}$ & $0 / 10^{a}$ & $0 / 10^{a}$ & $2 / 10^{\mathrm{a}}$ & $0 / 10^{\mathrm{a}}$ & $0 / 10^{\mathrm{a}}$ & $0 / 10^{a}$ \\
\hline
\end{tabular}

ab ;Different superscripts in the same row indicate significant difference $(p<0.05)$ among treatments for each parameter.

The values represent the number of chicks showing histopathological changes/number of chicks examined in each treatment group. $\left.{ }^{*} 1\right)$ Positive control diet, basal diet without additive (control); 2) Negative control diet, diet naturally contaminated with aflatoxin (NCD); 3) NCD supplemented with $1.5 \%$ SB; 4) NCD supplemented with 3\% SB; 5) NCD supplemented with $0.05 \%$ YG; 6) NCD supplemented with $0.1 \%$ YG ; 7) NCD supplemented with $1.5 \%$ SB+ $0.05 \%$ YG ; 8) NCD supplemented with $1.5 \%$ SB+ $0.1 \%$ YG ; 9 ) NCD supplemented with 3\% SB + 0.05\% YG; and 10) NCD supplemented with 3\% SB+0.1\% YG.SB = sodium bentonite. YG = Yeast Glucomannan. NS = Not significant, ** ( $p<0.05$ ). 


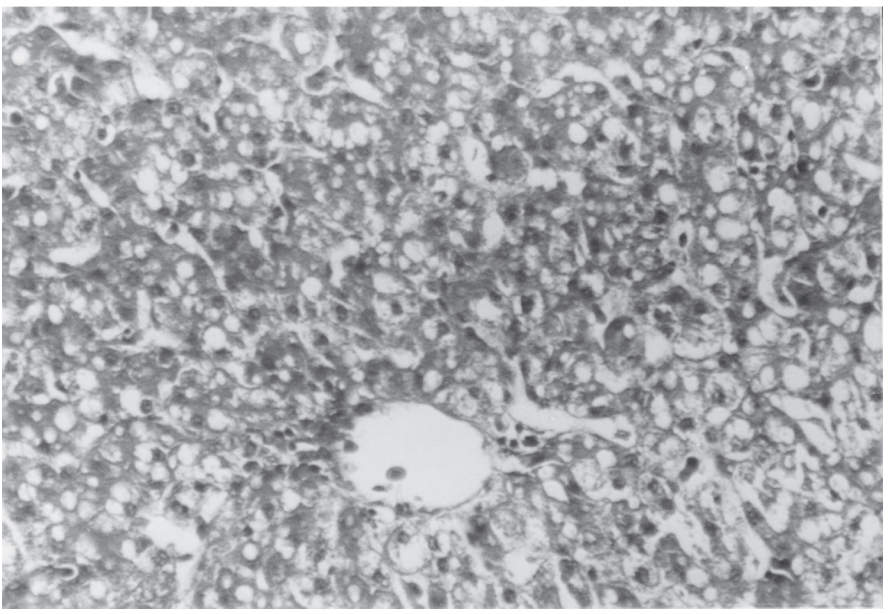

Fig 1. Histological section of the liver of a bird of the $250 \mathrm{ppb}$ aflatoxin -treated group showing marked fatty changes and moderate hydropic degeneration in hepatocytes $(\mathrm{H}$ \& $\mathrm{E} \times 300)$.

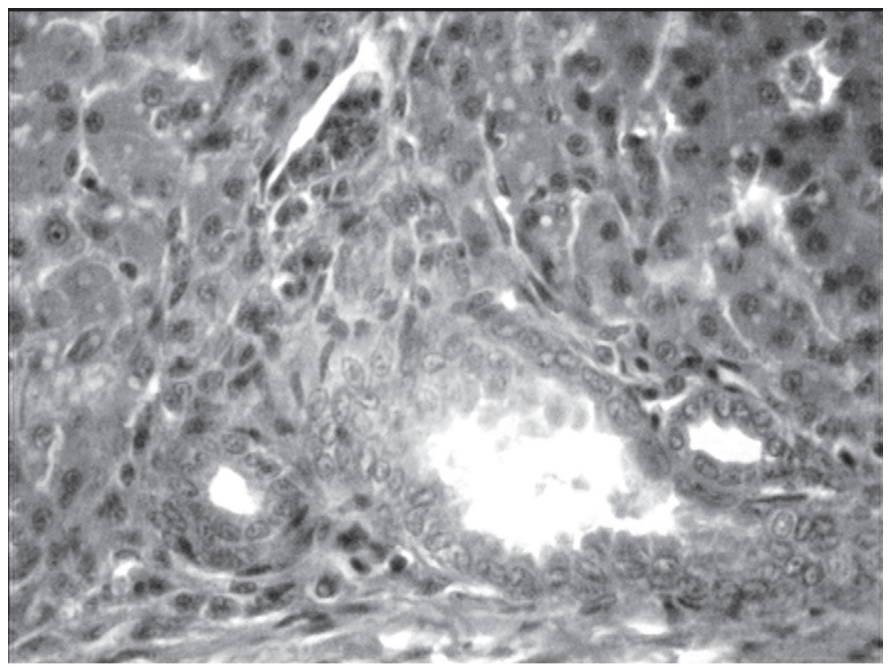

Fig 2. Liver of a bird of the $250 \mathrm{ppb}$ aflatoxin -treated group, showing bile-duct hyperplasia (H \& Ex300).

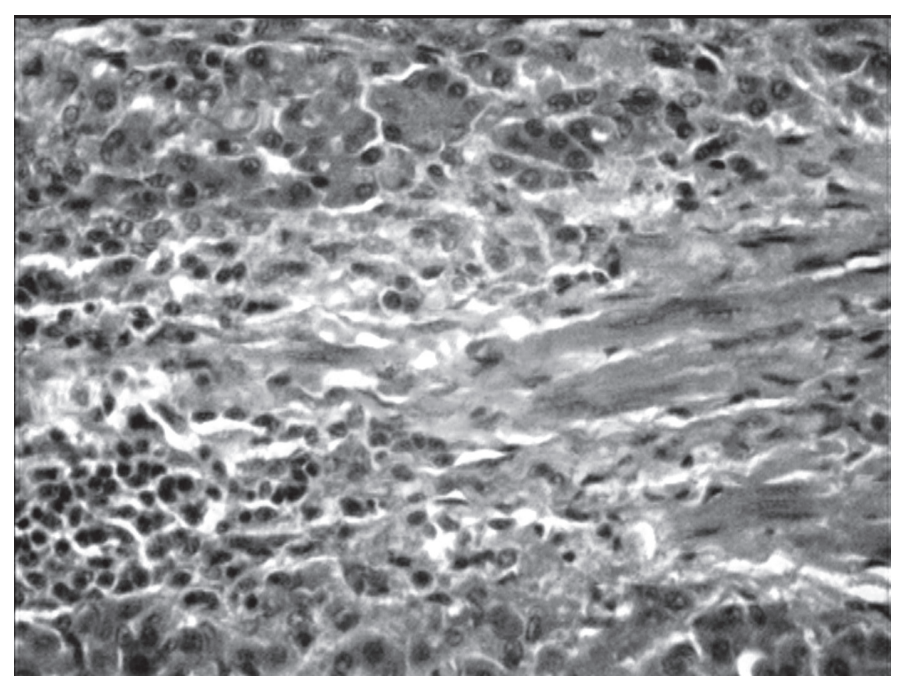

Fig 3. Liver of a bird of the $250 \mathrm{ppb}$ aflatoxin-treated group, showing mononuclear cell infiltration in the portal triad and connective tissue increase (H \& Ex300). reduced cholesterol and triglyceride values observed in the group fed the contaminated diet are a result of hepatic damage and leakage of enzymes in the bloodstream, as well as of impaired carbohydrate and lipid metabolism (Rosa et al., 2001; Mohamed \& Mohamed, 2009).

The gross and histopathological effects of aflatoxin on poultry are well-researched (Ortatatli \& Oguz, 2001). Our aim was to evaluate the impact of $250 \mathrm{ppb}$ aflatoxin, a level that has been shown to occur under field conditions, on pathological changes of the liver.

The liver is considered the primary target organ of aflatoxin (Ortatatli et al., 2005), and therefore, the livers of broilers were examined in the present study to determine if any pathological changes were present. In poultry, liver relative weight is increased by lower levels of aflatoxin more than that of other organs (Ortatatli \& Oguz, 2001). Hepatomegaly, hydropic and fatty changes, and acinar arrangements in hepatocytes, periportal fibrosis, and bile duct proliferation were detected in the present study, in agreement with previous findings (Karaman et al., 2005; Bintvihok, 2010). In the present study, liver relative weight was significantly higher in the negative control group compared with positive control group.

Removing aflatoxin from contaminated feeds and feedstuffs is still a major problem and there is a desperate need for efficient decontamination technologies (Oguz 2012; Rosa et al., 2012). An approach to the problem is the addition of non-nutritive and inert adsorbents and biological compounds produced by microorganisms, like bacteria or yeasts, to the diet to bind aflatoxin and to reduce its absorption in the gastrointestinal tract. In order to be effective, these compounds must not be absorbed in the gastrointestinal tract. They should also have the ability to physically bind to chemical substances, preventing their absorption (Che et al., 2011). In this study, YG and SB were selected as adsorbents for reducing aflatoxin absorption in the gastrointestinal tract and alleviating serum biochemical changes and lesions caused by the exposure to aflatoxin (250 ppb).

Several experiments evaluated the efficacy of the addition of $Y G$ and/or SB to aflatoxin-contaminated diets to alleviate the effects of aflatoxin toxicity on the performance, hematological, serum biochemistry, immune, and gross and histopathological changes of broilers (Aravind et al., 2003; Karaman et al., 2005; Ghahri et al., 2009; Magnoli et al., 2011; Rosa et al., 2012) and ducklings (Banlunara et al., 2005; Bintvihok, 2010). In most of the mentioned studies, YG and SB 
were added to diets contaminated with different levels of aflatoxin (200 to 2000 ppb). The present experiment was conducted to evaluate the effects of SB and $Y G$ (Mycosorb) in a diet naturally contaminated with $250 \mathrm{ppb}$ aflatoxin, which is considered as the level commonly present in field conditions.

When compared with the negative control group, the addition of $0.1 \%$ YG alone to the aflatoxincontaminated diet (250 ppb; group 6) significantly reduced the adverse effects of aflatoxin on AST and ALT activities and on liver relative weight, as well as the number of broilers affected and/or the severity of liver lesions. The other adsorbent treatments (groups $3,4,5,7,8,9,10)$ provided partial, but not statistically significant amelioration of the parameters influenced by the aflatoxin treatment. This means that the values of the biochemical and histopathological parameters obtained in these groups were intermediate between the positive and negative control groups. These effects may depend on the amount of aflatoxin molecules adsorbed in the gastrointestinal tract by the feed additives. It is predicted that, when more aflatoxin molecules are adsorbed by feed additives in the gastrointestinal tract, there are less negative effects on the target organs and blood biochemistry. These findings are in agreement with other studies reporting significant improvements with addition of YG in moldcontaminated diets (Aravind et al., 2003; Girish \& Devegowda, 2006; Che et al., 2011).

The effectiveness of $Y G$ to adsorb aflatoxin molecules in the gastrointestinal tract was clearly shown in our study, as predicted. The adsorbing effects of dietary YG are attributed to its ability to selectively bind to aflatoxin molecules. The cell wall of $S$. cerevisiae consists of a network of $\beta-1,3$ glucan backbone with $\beta-1,6$ glucan side chains, which in turn are attached to highly glycosylated mannan proteins, which make the external layer. The proteins and glucans provide numerous easily accessible binding sites with different binding mechanisms, such as hydrogen bonds, and ionic or hydrophobic interactions. The binding of aflatoxin to the yeast cell surface was reported earlier and it is attributed to cell wall glucans (Shetty et al., 2007; Guan et al., 2011).

When compared with negative control diet, the detoxifying efficacy of the inclusion of $1.5 \%$ and $3 \%$ SB in the aflatoxin-contaminated diet was not significant (groups 3, 4), in contrast with studies reporting significant amelioration of symptoms and lesions with the addition of SB (Eraslan et al., 2004; Miazzo et al., 2005; Magnoli et al., 2011) to diets containing aflatoxins (200 to $2500 \mathrm{ppb}$ ). The beneficial effects of
SB in the aforementioned studies may be attributed to its sequestering action, i.e., it adsorbs aflatoxins, reducing their bioavailability in the gastrointestinal tract. The differences between our results and these findings may be due to differences in sodium bentonite or aflatoxin levels in the feeds or to poultry species.

In a previous work (Mogadam \& Azizpour, 2011), we evaluated the toxic effects of aflatoxin (250 ppb) and the efficiency of dietary Mycosorb and SB addition to alleviate those effects on broiler performance and antibody production against Newcastle disease using the under the same experimental design as the present study. The amelioration of serum biochemical values and liver changes obtained with the diet contaminated with aflatoxin and with $0.1 \% \mathrm{YG}$ addition in the present study is consistent with the findings of that study, in which $0.1 \%$ YG proved to be effective for reducing the negative effects of aflatoxin on the performance and humoral immunity against ND.

\section{CONCLUSION}

The supply of the aflatoxin-contaminated diet (250ppb) significantly and negatively affected serum biochemical parameters and liver pathological changes of broilers. The addition of $Y G$ and $S B$, individually and in combination, to the aflatoxin-contaminated diet counteracted the negative effects of aflatoxin, but the supplementation to the aflatoxin-contaminated diet with $0.1 \%$ YG alone was much more effective than other treatments in ameliorating the adverse effects of aflatoxin on serum biochemical parameters and liver pathological changes.

\section{ACKNOWLEDGMENTS}

The authors are thankful to Dr.H. Ghahri from Islamic Azad University, Urmia, Iran for his technical help and Dr. AA. Farshid from Urmia University, Urmia, Iran for kindly providing Figures. The authors gratefully acknowledge the assistance of Prof. H. Oguz from Selcuk University, Campus, Konya, Turkey for reviewing of the manuscript.

\section{REFERENCES}

Azizpour A, Azizpour $Y$, Mogadam N. Evaluation of the effects of glucomannan-containing yeast product (Mycosorb) and sodium bentonite on serum biochemical parameters in broiler chickens during aflatoxicosis. Proceedings of the 1th International Conference on Biophysical Chemistry; 2012; Ardabil. Iran. P. 64.

Abousadi AM, Rowghani E, Ebrahimi HM. The efficacy of various additives to reduce the toxicity of aflatoxin B1 in broiler chicks. Iranian Journal of Veterinary Research 2007;19:144-150. 


\section{Effects of Yeast Glucomannan and Sodium Bentonite on the Toxicity of Aflatoxin in Broilers}

Aravind KL, Patil VS, Devegowda G, Umakantha B, Ganpule P. Efficacy of esterified glucomannan to counteract mycotoxicosis in naturallycontaminated feed on performance, serum biochemical and haematological parameters in broilers. Poultry Science 2003;82:570576.

Banlulara W, Bintvihok A, Kumagai S. Immunohistochemical study of proliferating cell nuclear antigen (PCNA) in duckling liver fed with aflatoxin B1 and esterified glucomannan. Toxin 2005;15:954-957.

Basmacioglu $H$, Oguz $H$, Ergul M, Col R, Birdane YO. Effect of dietary esterified glucomannan on performance, serum biochemistry and haematology in broilers exposed to aflatoxin. Czech Journal of Animal Science 2005;50:31-39.

Bintvihok A. Controlling AF danger to ducks and duck meat. World Poultry 2010;17:18-19.

Che Z, Liu Y, Wang H, Zhu H, Hou Y, Ding B. The protective effects of different mycotoxin adsorbents against blood and liver pathological changes induced by mold-contaminated feed in broilers. Asian Australasian Journal of Animal Sciences 2011;24:250-257.

Eraslan G, Akdogan M, Arsan E, Essiz D, Sahindokuyucu F, Hismiogullari SE, Altintas L. Effects of aflatoxin and sodium bentonite administered in feed alone or combined on lipid peroxidation in the liver and kidneys of broilers. Bulletin of the Veterinary Institute in Pulawy 2004;48:301-304.

Ghahri H, Talebi A, Chanmani M, Lotfollahian H, Afzali N. Ameliorative effect of EGM, SB, and humic acid on humoral immunity of broilers during chronic aflatoxicosis. Turkish Journal of Veterinary and Animal Sciences 2009;33:419-425.

Girish CK, Devegowda G. Efficacy of Glucomannan-containing Yeast Product (Mycosorb) and Hydrated Sodium Calcium Aluminosilicate in Preventing the Individual and Combined Toxicity of Aflatoxin and T-2 Toxin in Commercial Broilers. Asian - Australasian Journal of Animal Sciences 2006;19:877-883

Guan S, Zhou T, Yin Y, Xie M, Ruan Z, Young JC. Microbial strategies to control aflatoxins in food and feed. World Mycotoxin Journal 2011;4:413-424.

Ibrahim IK, Shareef AM, Al-joubory KMT. Ameliorative effects of sodium bentonite on phagocytosis and Newcastle disease antibody formation in broiler chickens during aflatoxicosis. Research in Veterinary Science 2000;69:119-122.

Karaman $M$, Basmacioglu $H$, Ortatatli $M$, Oguz $H$. Evaluation of the detoxifying effect of yeast glucomannan on aflatoxicosis in broilers as assessed by gross examination and histopathology. British Poultry Science 2005:46:394-400.

Kececi T, Oguz H, Kurtoglu V, Demet O. Effects of polyvinyl polypyrrolidone, synthetic zeolite and bentonite on serum biochemical and haematological characters of broiler chickens during aflatoxicosis. British Poultry Science 1998;39:452-458.

Khadem AA, Sharifi SD, Barati M, Borji M. Evaluation of the effectiveness of yeast, zeolite and active charcoal as aflatoxin absorbents in broiler diets. Global Veterinary 2012;8:426-432.

Magnoli AP, Monge MP, Miazzo RD, Cavaglieri LR, Magoli CE, Merkis Cl, et al. Effect of low levels of aflatoxin B1 on performance, biochemical parameters, and aflatoxin B1 in broiler liver tissues in the presence of monensin and sodium bentonite. Poultry Science 2011;90:48-58,

Manafi M, Umakantha B, Swamy HDN, Mohan K. Evaluation of high-grade sodium bentonite on performance and immune status of broilers, fed ochratoxin and aflatoxin. World Mycotoxin Journal 2009;2:435-440.

Manafi M. Counteracting effect of high grade sodium bentonite during aflatoxicosis in broilers. Journal of Agricultural Science and Technology 2012:14:539-547.

Miazzo R, Peralta MF, Magnoli C, Salvano M, Ferrero S, Chiacchiera SM, et al. Efficacy of sodium bentonite as a detoxifier of broiler feed contaminated with aflatoxin and fumonisin Poultry Science 2005;84:1-8.
Modirsanei M, Khosravi AR, Kiaei MM, Fard MHB, Gharagozloo MJ Khazraeinia P. Efficacy of dietary natural zeolite and Saccharomyces cereviceae in counteracting aflatoxicosis in broiler chicks. Journal of Applied Animal Research 2004;26:39-44

Mogadam N, Azizpour A. Ameliorative effect of glucomannan-containing yeast product (Mycosorb) and sodium bentoniteon performance and antibody titers against Newcastle disease in Broilers during Chronic Aflatoxicosis. African Journal Biotechnology 2011;10:17372-17378.

Mohamed AH, Mohamed AM. Heamato- biochemicaland pathological studies on aflatoxicosis and treatment of broilers chicks in Egypt. Veterinaria Italiana 2009;45:323-337

Mosca $V$, Marichal MJ. Effect of inclusion of anti-mycotoxin additives in naturally contaminated diets fed to broilers. Revista Argentina de Producción Animal 2011;31:55-62.

NRC - National Research Council. Nutrient requirements of poultry. 9th ed. Washington: National Academy of Sciences; 1994.

Oguz H. Detoxification of aflatoxin in poultry feed: a review from experimental trials. Lohmann Information 2012;47:45-56.

Oguz H, Kececi T, Birdane YO, Onder F, Kurtoglu, V. Effect of clinoptilolite on serum biochemical and haematological characters of broiler chickens during experimental aflatoxicosis. Research in Veterinary Science 2000;69:89-93

Oguz H, Nizmlioglu F, Dinc I, Uney K, Aydin, H. Determination of aflatoxin existence in mixed feed wheat flour and bulgur samples. Eurasian Journal of Veterinary Sciences 2011;27:171-175.

Ortatatli M, Oguz, H. Ameliorative effects of dietary clinoptilolite on pathological changes in broiler chickens during aflatoxicosis. Research in Veterinary Science 2001;71:59-66.

Ortatatli M, Oguz H, Hatipoglu F, Karaman, M. Evaluation of pathological changes in broilers during chronicAF (50 and $100 \mathrm{ppb}$ ) and $\mathrm{CLI}$ exposure. Research in Veterinary Science 2005;78:61-68.

Oznurlu Y, Celik I, Sur E, Ozaydin T, Oguz H, Altunbas, K. Determination of the effects of aflatoxin $\mathrm{B} 1$ given in ovo on the proximal tibial growth plate of broiler chickens: histological, histometric and immunohistochemical findings. Avian Pathology 2012;41:469-477.

Parlat SS, Ozcan M, Oguz, H. Biological suppression of aflatoxicosis in Japanese quail (Coturnixcoturnix japonica) by dietary addition of yeast (Saccharomyces cerevisiae). Research in Veterinary Science 2001:71:207-211.

Raju MVLN, Devegowda, G. Influence of esterified glucomannan on performance and organ morphology, serum biochemistry and haematology in broilers exposed to individual and combined mycotoxicosis (aflatoxin, ochratoxin and T-2 toxin). British Poultry Science 2000;41:640-650.

Romer RT. Screening methods for the detection of aflatoxins in mixed feeds and other agricultural commodities with subsequent confirmation and quantitative measurement of aflatoxins in positive samples. Journal of the Association of Official Analytical Chemists 1975;58:500-506.

Rosa CA, Miazzo R, Magnoli C, Salvano M, Chiac SM, Ferrero S, et al. Evaluation of the efficacy of bentonite from the south of Argentina to ameliorate the toxic effects of aflatoxin in broilers. Poultry Science 2001;80:139-144

Rosa AP, Uttpatel $R$, Santurio JM, Sher A, Duarte $V$, Santos $C B$, et al. Performance of broilers derived from breeder hens fed with diets containing aflatoxins and esterified glucomannan as adsorbent. Brazilian Journal of Animal Science 2012;41:347-352.

SAS. Statistical analysis system, Cary: SAS Institute; 1996

Shetty PH, Hald, B, Jespersen, L. Surface binding of aflatoxin B1 by Saccharomyces cerevisiae strains with potential decontaminating abilities in indigenous fermented foods. International Journal of Food Microbiology 2007;113:41-46. 
